\title{
Pherdinterti
}

International Journal of PharmTech Research CODEN (USA): IJPRIF, ISSN: 0974-4304, ISSN(Online): 2455-9563

\section{An Endeavour to Enhance the Yield of Adjuvant (Active Vaccine Emulsifier) from Esterification}

\author{
*Savita Belwal, N.Narasimha Naidu, V.S.Aravindand M. Bhagvanth Rao \\ Department of Chemistry, Department of Chemical Engineering, Anurag Group \\ of Institutions, Hyderabad, Telangana (India)
}

\begin{abstract}
An effort has been made to enhance the yield by changing the parameters of the experiment for the literature reported novel adjuvant-active compound which is used to increase the immunogenicity of many kinds of antigens and used as active vaccine emulsifier. The compound, novel adjuvant-active saccharide oleate ester was isolated, characterized and its yield has been verified and compared with the literature. The compound is separated from the product mixture synthesized from mannitol and oleic acid esterification. The mixture, which contained many kinds of mannide mono- and dioleates and their derivatives, was fractionated by liquid chromatography (LC) and $\mathrm{R}_{\mathrm{f}}$ values of all the three fractions were obtained by TLC method.

By changing the range of temperature and using four different catalysts (sulphuric acid, phosphoric acid, methane sulphonic acid, p-toluene sulphonic acid) different results are obtained. It has been observed that yield has been increased for the p-toluene sulphonic acid catalytic reaction after the rotary evaporation for the fraction three (3) which is obtained after the column chromatography. Characterization of the compound has been donewith the help of $\mathrm{UV}, \mathrm{IR}, \mathrm{XRD}$, and HPLC.

Keywords : Mannidemonooleate; Oligosaccharide oleate ester, Column Chromatography, Rotary Evaporator, UV, IR, XRD, and HPLC.
\end{abstract}

\section{Introduction}

The word adjuvant is derived from the Latin word adiuvare; meaning to help or assist, referring to any material that augments the cellular or humoral response to an antigen ${ }^{1}$. They comprise a diverse group of defined molecules or more complex formulations and have been used since the early 20th century to help improve this response ${ }^{2}$. The need for adjuvants has arisen because many vaccines produce a poor immunological response on their own.

\subsection{Need for adjuvants}

Vaccines, one of the most successful medical inventions against various infectious diseases, (Hillman), sometimes require a molecule in conjugation that enhances its immune response. Previously, antibodies used to be made in response to carbohydrates, proteins, complex lipids and nucleic acids which had been isolated from 
natural sources. Though, the antigens today are made using modern chemical, biosynthetic and rDNA techniques; a majority of which are weak immunogens due to the lack of an innate immune stimulus. Small polypeptides $(<10 \mathrm{kDa})$ and nonprotein antigens need to be conjugated to a large immunogenic carrier protein to become good immunogens. It is therefore expedient to co-administer these with an adjuvant to ensure a high quality/high quantity, memory-enhanced antibody response $\mathrm{e}^{3,4}$.

\subsection{Adjuvants can be subjected to various uses such as:}

1. To reinforce the immune response to any antigens by delivering in native form.

2. To reduce the multiple immunization protocols for protective immunity. In specifically to develop single step vaccination coverage that can reduce the vaccination costs.

3. To fortify the immune response of immune compromised adults and weakened the immune system of children, to elicit cytotoxic T lymphocytes response and generate the local immune response.

\subsection{Classification of adjuvants:}

The adjuvant property of a molecule increases with the length of the sugar side chain and the HLB value has high hydrophilic-lipophilic balance (HLB) value. However, adjuvants are conventionally classified into the following categories: Mineral compounds, Bacterial products, Oil-based emulsions, ISCOMs, and Liposomes. Of these, the aluminum based mineral compounds are the most widespread and the most preferred for humans ${ }^{5-7}$.

There are many kinds of adjuvant compounds, such assaponins ${ }^{8}$ lipid A derivatives, muramyldipeptide, and carbohydrate polymers, that improve vaccine potency. Oil-based adjuvants ${ }^{9}$ have also been developed and used in practice as essential constituents that increase the immunogenicity of many kinds of antigens in veterinary emulsion vaccines ${ }^{10,11}$. For instance, Freund's complete and incomplete adjuvants (FCA and FIArespectively) ${ }^{12-14}$, TiterMax® ${ }^{\circledR} \operatorname{series}^{15}$, Montanide ${ }^{\circledR}$ ISA series ${ }^{16}$ and many other preparations (e.g. Pluronic $\AA$ and Tetronic ${ }^{\circledR}$ series ${ }^{17}$ and GERBU adjuvants ${ }^{18}$ are commercially available. They contain agents such as bacterial products from Mycobacterium (in FCA), non-ionic block copolymers (in TiterMax ${ }^{\circledR}$ series, and Pluronic $\AA$ and Tetronic $® s e r i e s$ ), and (or) mannidemonooleate (MMO) (inFCA, FIA, Montanide ${ }^{\circledR}$ ISA series, and GERBU adjuvants) as essential ingredients for strong adjuvanticity.

One of the representative ingredients of oil-based adjuvants, MMO mixture, has been widely used as an emulsifier for many veterinary vaccines. Intense investigations of this compound mixture, named Arlacel A, were carried out in the 1960s and 1970s, and this mixture has been shown to be an excellent adjuvant in both laboratory and practical applications. Recently, MMO contained in some commercial vaccine adjuvants has been produced and highly refined using advanced technology to avoid undesirable reactogenicity and the adjuvants have been tested in human phase I trials ${ }^{19,20}$. At the same time, several tasks have remained to be solved. Synthesizing such adjuvants ${ }^{21,22}$ reproducibly on a commercial scale requires high technical skill in order to avoid lot-to-lot variations that may result from methods with lower specificity. Such low-specificity synthesis processes cause heterogeneous mixtures of products mainly consisting of many kinds of mannide mono- and dioleates, and their derivatives Moreover the compounds with the highest adjuvanticity of all the mannideoleates and their derivatives in such heterogeneous product mixtures have not been fully identified ${ }^{23,25}$.

Such heterogeneous product mixtures might contain novel compounds other than the already known mannideoleates with high adjuvanticity has been confirmed Japanese scientists during their research of nearly 30 years and developed ${ }^{26}$ such a mixture, one product of a certain esterification process between mannitol and oleic acid was obtained. One fraction that was further separated from the product mixture showed high adjuvanticity in mice under dispersed conditions without base oil. In this study, they tried to isolate the compound with the highest adjuvanticity from the product mixture and characterize the isolated compound by an integrated approach using physicochemical analysis, consideration of the reaction process, and comparison of adjuvanticity with other analogous compounds which are already known to be a good adjuvant. Furthermore, they tested the usefulness of the compound for laboratory and practical applications in comparison with other representative adjuvant constituents. 


\section{Material and methods}

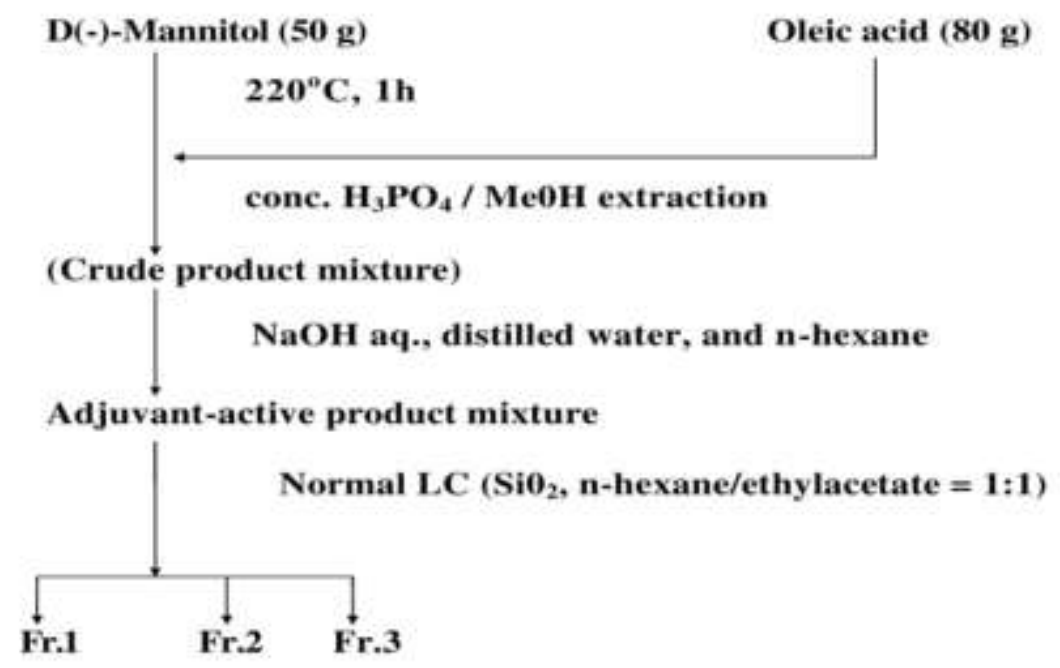

Figure 1: Process Flow Diagram for esterification

The adjuvant-active product mixture was chemically synthesized by esterification between sugar and fatty acid under strongly acidic conditions.

Fifty grams of D-(-)-mannitol was fused at $220{ }^{\circ} \mathrm{C}$ for $1 \mathrm{~h}$. Catalyst(concentrated sulphuric acid, phosphoric acid, methane sulphonic acid, p-toluene sulphonic acid)and $80 \mathrm{~g}$ of oleic acid were gradually dropped into the fused mannitol being mixed slowly. The mixture was stirred and heated continuously at $220{ }^{\circ} \mathrm{C}$ for $2 \mathrm{~h}$. The reaction mixture was then cooled to room temperature and extracted with methanol. The methanol extract was neutralized with aqueous $\mathrm{NaOH}$ and washed with distilled water to remove the phosphates and free mannitol residues. It was further washed with $n$-hexane to remove free oleic acid and dried to give the adjuvantactive product mixture as MMO fraction.

It was a brown viscous paste, had a slight ester fragrance, and was easily dispersed in water to yield a milky white suspension.

\subsection{Preparative normal-phase liquid chromatography (normal LC) and reverse-phase high performance liquid chromatography(RP-HPLC):}

The normal LC was performed on Silica gel column (50 mm i.d., $500 \mathrm{~mm}$ length) using nhexane/ethylacetate $(1: 1)$ as solvent at a flow rate of $10 \mathrm{ml} / \mathrm{min}$.

\subsection{Preparation of the Column and Adding the Sample to the Column:}

Place the column in a ring stand in a vertical position. A plug of glass wool is pushed down to the bottom of the column. Prepare the slurry of silica gel with a suitable solvent \& pour gently into the column. Open the stop cock \& allow some solvent to drain out. The layer of solvent should always cover the adsorbent; otherwise, cracks will develop in the column. Dissolve the sample mixture in a minimum amount of solvent $(n$ hexane and ethylacetate mixture) and silica gel. Remove the solvent by placing the mixture in a hot air oven at a low temperature. Place the dry powder on a piece of weighing paper and transfer it to the top of the column through the funnel.

\subsection{Developing the Chromatogram:}

Attach a dropping funnel filled with solvent on to the column. Add the solvent mixture continuously from the funnel to the top of the column. Open the stopcock carefully. The components of the mixture run down the column forming separate bands. 


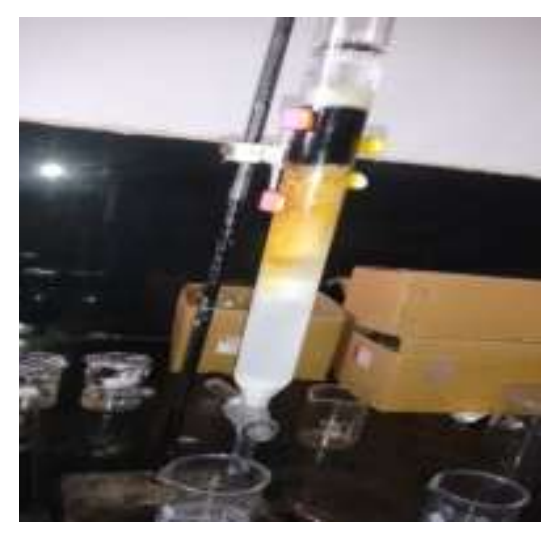

Figure 2:Column Chromatography

\subsection{Recovering the Constituents:}

Continue running the solvent till both the bands are eluted out separately. Collect the constituents in different beakers or test tubes.

\subsection{Thin layer chromatography:}

Samples were developed on Silica gel 60 TLC plates with $20 \%$ of 1-propanol in $n$-hexane at room temperature. After development, $1 \mathrm{M}$ sulfuric acid was sprayed over the TLC plate, and the plate was evenly heat-treated at $120{ }^{\circ} \mathrm{C}$ for coloration of the spots. According to those spots, three fractions are obtained.

$\mathbf{R}_{\mathrm{f}}$ value equation: $\frac{\text { Distancetraveled by spot }}{\text { Totaldistance }}$

\section{Rotary evaporation}

The three fractions were separately taken for rotary evaporation and thick liquor was obtained by evaporating the solvent mixture (n-hexane/ethyl acetate).

Table 1: Yields of Fraction 3 with Different Catalyst

\begin{tabular}{|l|l|l|l|l|l|l|l|l|}
\hline S.no & Catalyst & $\begin{array}{l}\text { Mannitol } \\
\text { (grams) }\end{array}$ & $\begin{array}{l}\text { Oleic } \\
\text { acid } \\
\text { (grams) }\end{array}$ & $\begin{array}{l}\text { Temperature } \\
(\mathbf{0} \mathbf{c})\end{array}$ & $\begin{array}{l}\text { Yield of } \\
\text { fraction 3 } \\
\text { (for 4 } \\
\text { grams) }\end{array}$ & $\begin{array}{l}\mathbf{R}_{\mathbf{f}} \\
\text { values }\end{array}$ & $\begin{array}{l}\text { \% } \\
\text { yield }\end{array}$ \\
\hline 1. & & Sulphuric acid & 50 & 80 & $200-230$ & 0.22 & 0.294 & 5.5 \\
\hline 2. & $\begin{array}{l}\text { Phosphoric } \\
\text { acid }\end{array}$ & 50 & 80 & $200-230$ & 0.55 & 0.51 & 13.75 \\
\hline 3. & $\begin{array}{l}\text { Methane } \\
\text { sulphonic acid }\end{array}$ & 50 & 80 & $200-230$ & 0.54 & 0.65 & 13.5 \\
\hline 4. & $\begin{array}{l}\text { Para-toluene } \\
\text { sulphonic acid }\end{array}$ & 50 & 80 & $200-230$ & $\mathbf{0 . 8 9}$ & 0.343 & 22.25 \\
\hline
\end{tabular}

\section{Results and Discussion}

\subsection{Ultra violet -visible spectroscopy :}

In this region of the electromagnetic spectrum, atoms and molecules undergo electronic transitions. Spectra of compounds show the presence $\pi$ bond and absence of conjugation and aromatic rings. Absorption spectroscopy is complementary to fluorescence spectroscopy, in that fluorescence deals with transitions from the excited state to the ground state, while absorption measures transitions from the ground state to the excited state. A band at $260 \mathrm{~nm}$ was observed due to the $\mathrm{C}=\mathrm{C}$ bond of the resulting compound shows the presence of $\pi$ $\pi *$ transitions. 


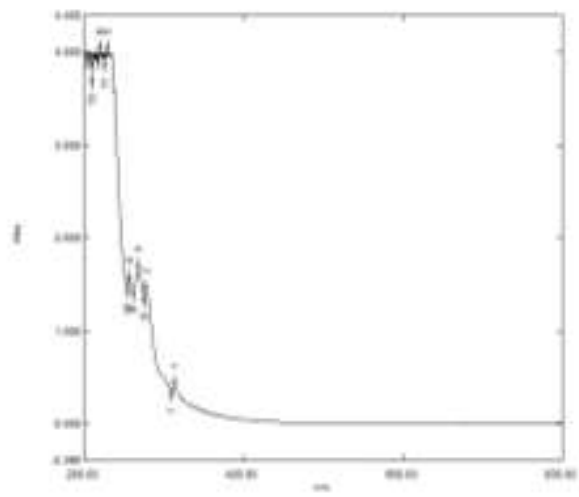

Figure 3: UV-Visible Spectrum of Fraction 3

\subsection{Infrared spectroscopy analysis:}

The graph shown below is the fraction3 of the catalyst para toluene sulphonic acid. FTIR spectrum of the prepared liquid sample indicated the presences of some functional groups of hydrocarbon and oxygen. The IR spectra of the fraction 3 show medium intensity bands in region $1735 \mathrm{~cm}^{-1}$ due to $\mathrm{C}-\mathrm{O}$ stretching vibration. The two sharp bands around $2922 \mathrm{~cm}^{-1}$ and $3370 \mathrm{~cm}^{-1}$ due to $\mathrm{C}-\mathrm{H}$ stretching vibration and $\mathrm{O}-\mathrm{H}$ stretching vibration. Several new bands in the complexes at 1465,1383 and $1327 \mathrm{~cm}^{-1}$ are due to $\mathrm{C}-\mathrm{H}$ bending vibrations in $\mathrm{CH}_{3}$ groups

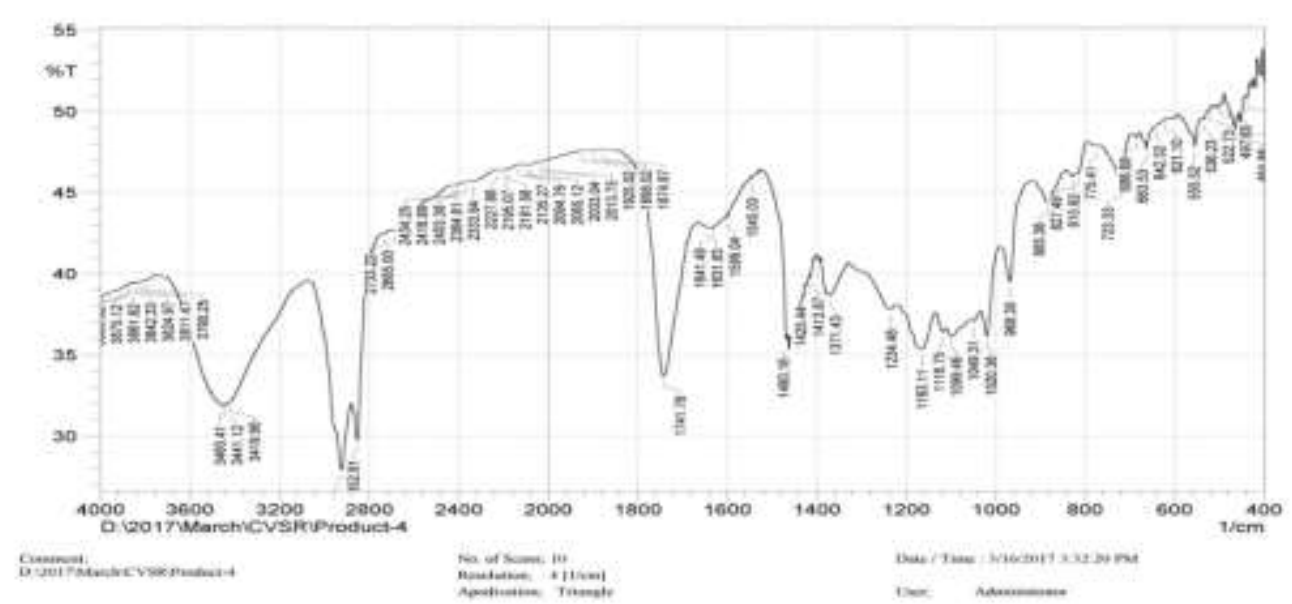

Figure 4: FTIR spectrum of fraction3obtained from para toluene sulphonic acid catalyst

\subsection{High- performance liquid chromatography:}

High-performance liquid chromatography (HPLC) is basically a highly improved form of column chromatography. Instead of a solvent being allowed to drip through a column under gravity, it is forced through under high pressures of up to 400 atmospheres. Because of this, it is much faster.

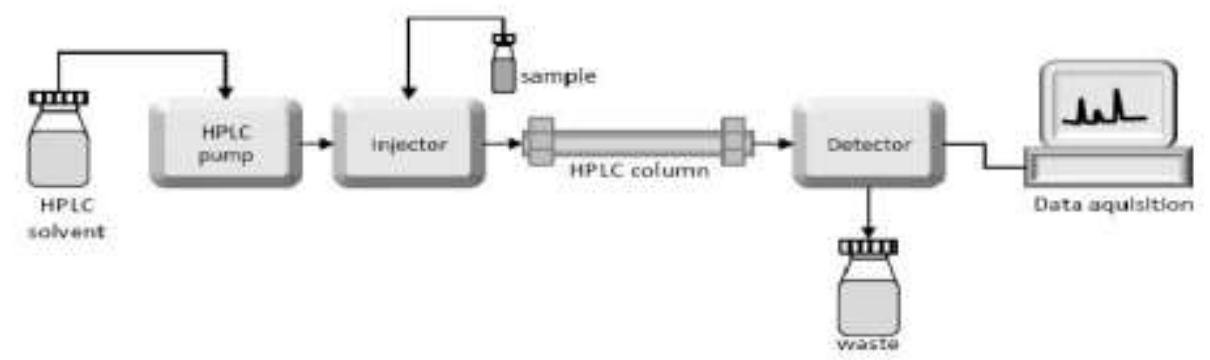

Figure 5: HPLC Flow Sheet 
The separation and quantitative determination of fatty acids were performed by high-performance liquid chromatography employing a C18 column and an isocratic elution method coupled to ultraviolet detection. The analytical enzymatic procedure is sensitive for $<0.5 \mu \mathrm{g} / \mathrm{mL}$ of FFAs in a reduced sample of $0.1 \mathrm{mg}$ of drying oil.

The fatty acids generally found are monounsaturated, such as oleic acid (18:1), and polyunsaturated such as linoleic acid (18:2) and linolenic acid (18:3), and also include saturated fatty acids such as palmitic acid and stearic acid. The drying power of an oil is in relation to its chemical composition.

\section{HPLC of Oleic Acid $\left(\mathrm{C}_{18} \mathrm{H}_{34} \mathrm{O}_{2}\right)$}

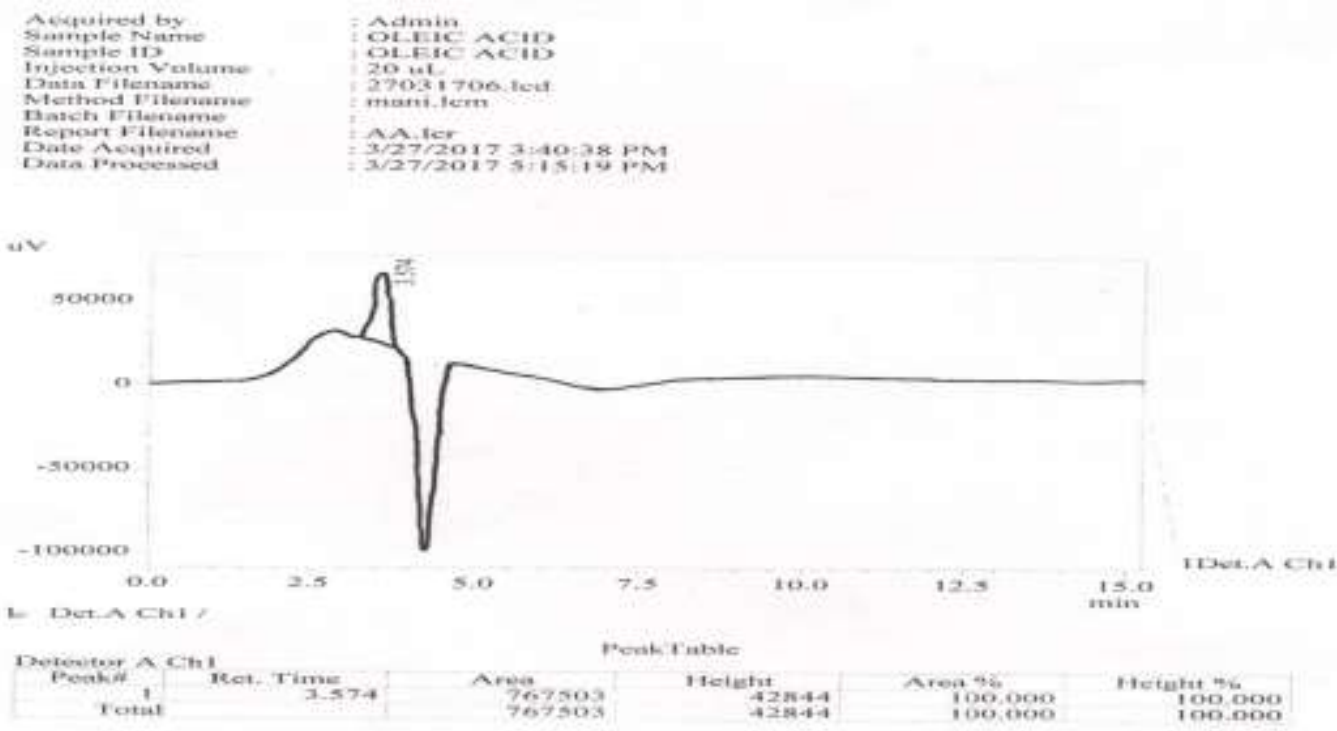

Figure 6: HPLC of Oleic Acid

\section{HPLC of Mannitol}

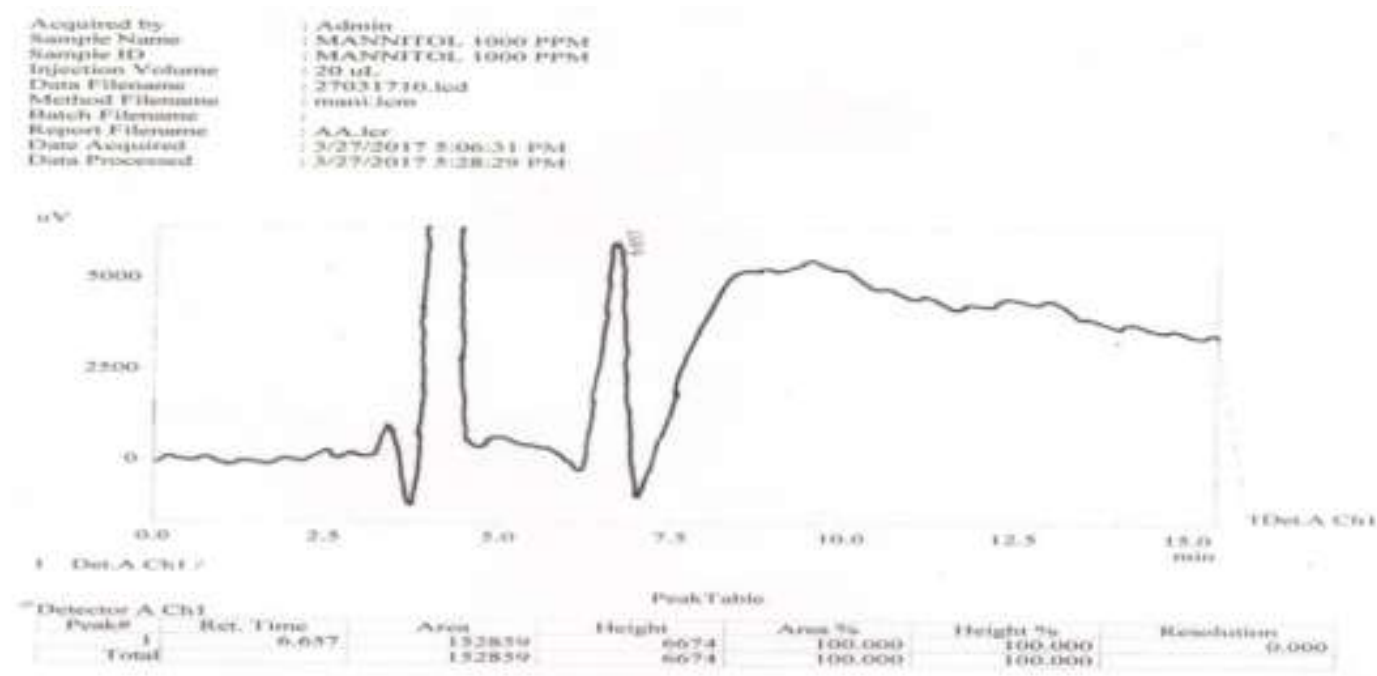

Figure 7: HPLC of Mannitol

To determine the mannitol content of the sample liquid chromatography is used. The liquid chromatograph (HPLC) using differential refractometer maintained at a constant temperature used for detection. The column used for detection is AMINEX HPX $87 \mathrm{C}$ (resin in calcium form), length $30 \mathrm{~cm}$, and internal diameter $9 \mathrm{~mm}$. Double distilled degassed water (filtered through Millipore membrane filter $0.45 \mu \mathrm{m}$ ) was used as Eluent. 


\section{HPLC of Adjuvant Active Product Mixture (PTSA)}

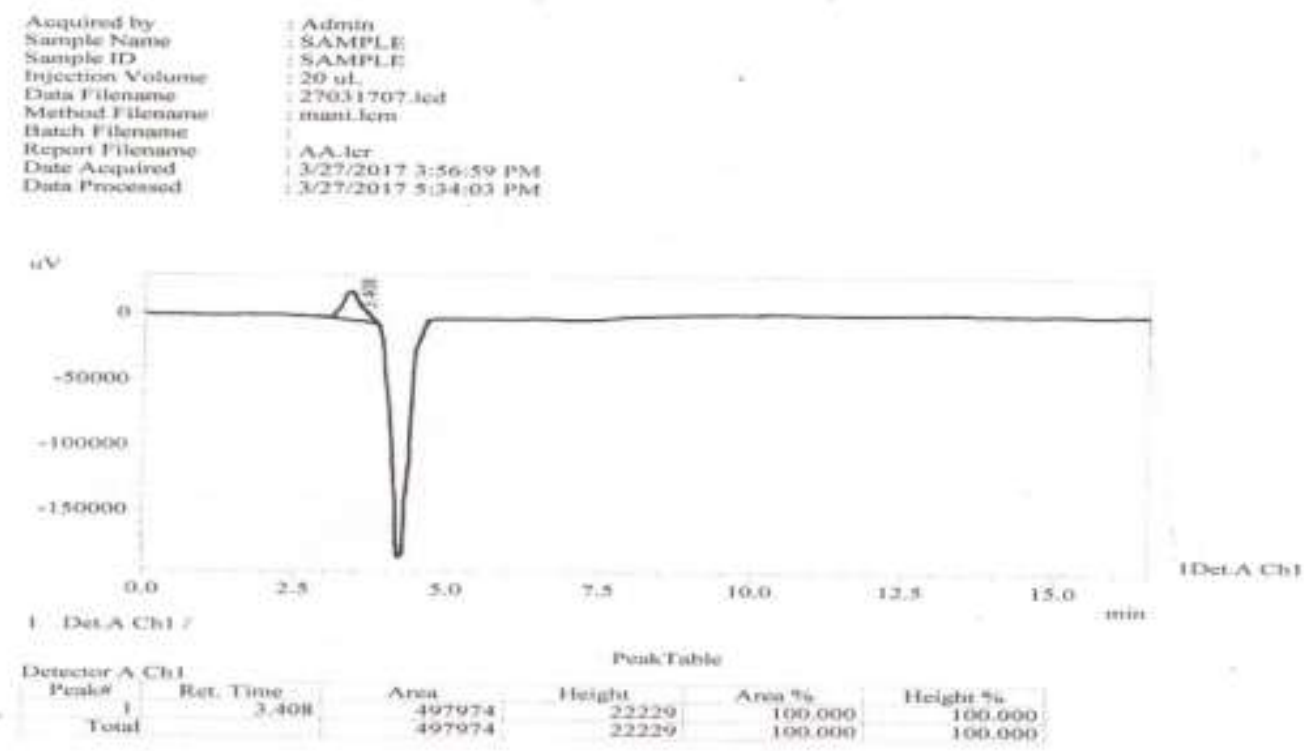

Figure 8: HPLC of Adjuvant Active Product Mixture

It is oligosaccharide oleate ester which is product mixture of esterification between mannitol and oleic acid. It has hydrophilic saccharide backbone and lipophilic acylate domains separated by RP-HPLC as more lipophilic fraction than mannitol.

\subsection{X-Ray Diffraction:}

$\mathrm{X}$-ray powder diffraction (XRD) is a rapid analytical technique primarily used for phase identification of PTSA material to get information on unit cell dimensions. After analysis material is finely ground, homogenized, and average bulk composition is determined. This diffractogram shows a set of three reflections with the higher relative intensity, for $2 \theta \approx 16.461,22.670$ and $28.343^{\circ}$. Distinct reflections of lower intensity can be distinguished from the diffractograms, for $2 \theta \approx 9.27,15.337$ and $12.947^{\circ}$. The appearance of peaks indicates significant crystallization of PTSA, indicating that some part of the PTSA sub chains become rigid and well ordered.

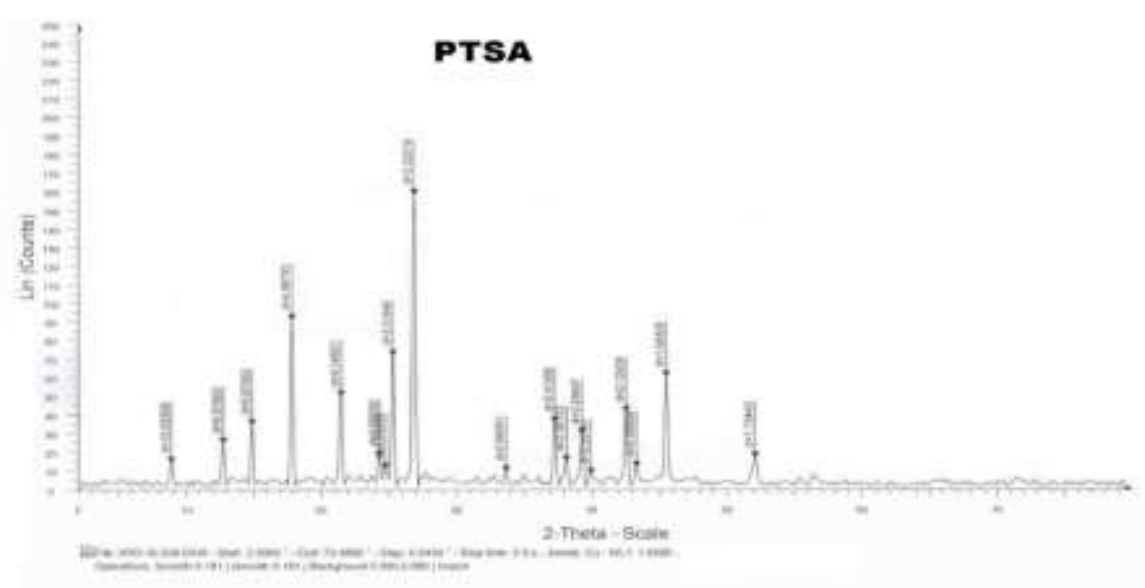




\subsection{Conclusion:}

In this study, an oligosaccharide oleate ester with strong adjuvanticity was obtained from the product mixture of esterification between mannitol and oleic acid. The result revealed that the ester was one of the adjuvant-active compounds which are contributing to the excellent adjuvanticity of and used as a vaccine emulsifier. The present results and previous findings suggest that the fundamental adjuvanticity of 'oligo' saccharide acylate ester is also accounted taking into consideration of the hydrophilic saccharide backbone and lipophilic acylate domains. This ester is expected to be useful as one of the novel type adjuvants both in the particulate form and as an emulsifier for oil-based. It also indicated the possibility that novel and unique adjuvant compounds still remain to be identified from such heterogeneous type adjuvants.

\subsection{Future Scope:}

Research work has been in progress to increase the yield and optimize the production cost. Many research programs will be initiated as there is an increase in the demand for vaccines. Optimization of the production cost has been a major task as the cost of the chemicals is high.

Many developed countries and few developing countries have already initiated their research programs and are trying to change the various parameters to increase the efficiency and planning to make it available to common man so that every vaccine with adjuvant can increase the immune towards the antigen.

These days generic medicine become more usage than the normal ones if the adjuvants are added to these generic medicines, various diseases can be cured in an instant.

French industries are trying to economize the cost of the production as they are the only one who is producing this adjuvant at a cost of rupees five lakh per $\mathrm{Kg}$. If this is reduced to fifty percent then it will be a huge success in the chemical and pharmaceutical industry.

\section{References}

1. Segura, M. (2015). Streptococcus suis vaccines: candidate antigens and progress. Expert Review of Vaccines, 14(12), 1587-1608. doi:10.1586/14760584.2015.1101349.

2. Martins, K. A., Bavari, S., \& Salazar, A. (2015). Vaccine adjuvant uses of poly-IC and derivatives. Expert Review of Vaccines, 14(3), 447-459. doi:10.1586/14760584.2015.966085.

3. Lawrence, G. W., Saul, A., Giddy, A. J., Kemp, R., \& Pye, D. (1997). Phase I trial in humans of an oilbased adjuvant SEPPIC MONTANIDE ISA 720. Vaccine, 15(2), 176-178. doi:10.1016/S0264$\underline{410 X(96) 00150-8}$.

4. Oda, K., Sato, Y., Katayama, S., Ito, A., \& Ohgitani, T. (2004). Separation and characterization of adjuvant oligosaccharide oleate ester derived from product mixture of mannitol-oleic acid esterification. Vaccine, 22(21-22), 2812-2821. doi:10.1016/j.vaccine.2004.01.047.

5. P AiyerHarini, HG Ashok Kumar, G Praveen Kumar, N Shivakumar, (•••).An overview of immunologic adjuvants-A review. Journal of Vaccines \& Vaccination, 4(1), 1-4.

6. Amy, S., McKee, Michael W. Munks, Philippa Marrack, (2007). How Do Adjuvants Work? Important Considerations for New Generation Adjuvants, 27(5), 687-690.

7. Rivera, E., Daggfeldt, A., \& Hu, S. (2003). Ginseng extract in aluminium hydroxide adjuvanted vaccines improves the antibody response of pigs to porcine parvovirus and Erysipelothrixrhusiopathiae. Veterinary Immunology and Immunopathology, 91(1), 19-27. doi:10.1016/S0165-2427(02)00269-6.

8. Oda, K., Matsuda, H., Murakami, T., Katayama, S., Ohgitani, T., \& Yoshikawa, M. (2000). Adjuvant and haemolytic activities of 47 saponins derived from medicinal and food plants. Biological Chemistry, 381(1), 67-74. doi:10.1515/BC.2000.009.

9. Leenaars, M., Koedam, M. A., Hendriksen, C. F., \& Claassen, E. (1998). Immune responses and side effects of five different oil-based adjuvants in mice. Veterinary Immunology and Immunopathology, 61(24), 291-304. doi:10.1016/S0165-2427(97)00133-5.

10. Feng, Y., Pan, X., Sun, W., Wang, C., Zhang, H., Li, X., \& Tang, J. (2009). Streptococcussuisenolase functions as a protective antigen displayed on the bacterial cell surface. The Journal of Infectious Diseases, 200(10), 1583-1592. doi:10.1086/644602. 
11. Goyette-Desjardins, G., Calzas, C., Shiao, T. C., Neubauer, A., Kempker, J., Roy, R., . ., \& Segura, M. (2016). Protection against Streptococcus suis Serotype 2 Infection Using a Capsular Polysaccharide Glycoconjugate Vaccine. Infection and Immunity, 84(7), 2059-2075. doi:10.1128/IAI.00139-16.

12. Jensen, F. C., Savary, J. R., Diveley, J. P., \& Chang, J. C. (1998). Adjuvant activity of incomplete Freund's adjuvant. Advanced Drug Delivery Reviews, 32(3), 173-186. doi:10.1016/S0169409X(98)00009-X.

13. Stils, H. F. (2005). Adjuvants and Antibody Production: Dispelling the Myths Associated with Freund's Complete and Other Adjuvants. ILAR Journal, 46(3), 280-293. doi:10.1093/ilar.46.3.280.

14. Heegaard, P. M., Dedieu, L., Johnson, N., Le Potier, M. F., Mockey, M., Mutinelli, F., \& Sørensen, N. S. (2011). Adjuvants and delivery systems in veterinary vaccinology: current state and future developments. Archives of Virology, 156(2), 183-202. doi:10.1007/s00705-010-0863-1.

15. CytRx Corp. TiterMax®. Data file. Georgia, USA.

16. Seppic. Montanide ${ }^{\circledR}$ ISA series. Catalog data files. Paris, France.

17. Wyandotte Chemicals Corp. and BASF Performance Chemicals. Pluronic $®$ and Tetronic $®$ series. Data file. New Jersey, USA.

18. GERBU Biochemicals GmbH. GERBU adjuvants, Technical data sheets. Gaiberg, Germany.

19. Toledo, H., Baly, A., Castro, O., Resik, S., Laferté, J., Rolo, F., \& Duarte, C. A. (2001). A phase I clinical trial of a multi-epitope polypeptide TAB9 combined with Montanide ISA 720 adjuvant in non-HIV-1 infected human volunteers. Vaccine, 19(30), 4328-4336. doi:10.1016/S0264-410X(01)00111-6.

20. Saul, A., Lawrence, G., Smillie, A., Rzepczyk, C. M., Reed, C., Taylor, D., \& Stürchler, D. (1999). Human phase I vaccine trials of 3 recombinant asexual stage malaria antigens with Montanide ISA720 adjuvant. Vaccine, 17(23-24), 3145-3159. doi:10.1016/S0264-410X(99)00175-9.

21. Crawley, A., \& Wilkie, B. N. (2003). Porcine Igisotypes:Function and molecular characteristics. Vaccine, 21(21-22), 2911-2922. doi:10.1016/S0264-410X(03)00142-7.

22. Petrovsky, N., \& Aguilar, J. C. (2004, October). Vaccine adjuvants: current state and future trends. Immunology and Cell Biology, 82(5), 488-496. doi:10.1111/j.0818-9641.2004.01272.x.

23. Gerdts, V. (2015). Adjuvants for veterinary vaccines--types and modes of action. Berliner und Munchener Tierarztliche Wochenschrift, 128(11-12), 456-463.

24. Heegaard, P. M., Fang, Y., \& Jungersen, G. (2016). Novel Adjuvants and Immunomodulators for Veterinary Vaccines. Methods in Molecular Biology (Clifton, N.J.), 1349, 63-82. doi:10.1007/978-14939-3008-1 5 .

25. Lecours, M. P., Segura, M., Lachance, C., Mussa, T., Surprenant, C., Montoya, M., \& Gottschalk, M. (2011). Characterization of porcine dendritic cell response to Streptococcus suis. Veterinary Research, 42(1), 72. doi:10.1186/1297-9716-42-72.

26. Oda, K., Sato, Y., Katayama, S., Ito, A., \& Ohgitani, T. (2004). Separation and characterization of adjuvant oligosaccharide oleate ester derived from product mixture of mannitol-oleic acid esterification. Vaccine, 22(21-22), 2812-2821. doi:10.1016/j.vaccine.2004.01.047.

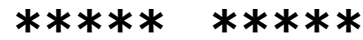

